\title{
A1C e o controle glicêmico: um desafio para todos
}

Estudo recentemente desenvolvido pela Universidade Federal de São Paulo (UNIFESP) e pela Fundação Oswaldo Cruz (FIOCRUZ) da Bahia avaliou o estado atual do controle glicêmico no Brasil, realizando determinações dos níveis de hemoglobina glicada (A1C) de 6.700 pacientes distribuídos em 10 cidades de oito estados brasileiros e do Distrito Federal. O resultado foi alarmante: o mau controle do diabetes, definido por uma A1C acima de 7\%, foi constatado em quase $90 \%$ dos portadores de diabetes mellitus tipo 1 (DM1) e em cerca de $73 \%$ dos portadores de DM2.

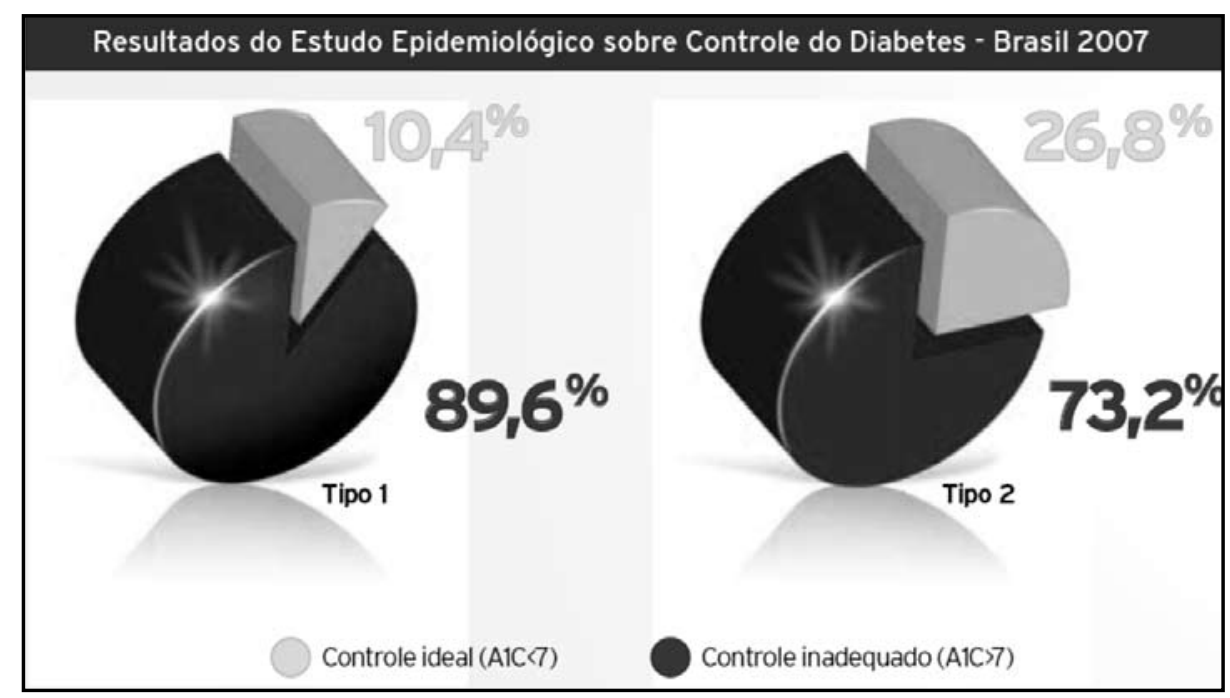

Fonte: Mendes ABV, Moreira Jr ED and Chacra, AR. Evaluation of glycemic control in a population based sample of patients with diabetes in Brazil. In: American Diabetes Association's Scientific Sessions, 68, 2008, San Francisco, CA.

Diante de um problema dessa magnitude fica plenamente justificada a ação conjunta entre a Sociedade Brasileira de Patologia Clínica/Medicina Laboratorial (SBPC/ML) e as entidades nacionais ligadas ao diabetes, como a Sociedade Brasileira de Diabetes (SBD), a Sociedade Brasileira de Endocrinologia e Metabologia (SBEM) e a Federação Nacional de Associações e Entidades de Diabetes (FENAD).

Essa iniciativa é um exemplo concreto da necessidade urgente de diálogo entre entidades médicas de diferentes áreas que cuidam diretamente das principais patologias de interesse em saúde pública, sendo o diabetes uma das mais importantes, tendo em vista seu alto grau de morbimortalidade.

Esse conjunto de entidades ainda tem um longo trabalho de educação em saúde a ser desenvolvido para atingir tanto os profissionais de saúde como os portadores de diabetes no sentido de convencê-los da importância da realização frequente de testes de A1C. Esta terceira edição do Posicionamento Oficial sobre a A1C é a resposta dessas entidades ao grande desafio que é de todos nós: a educação para a prevenção. 